\title{
A New Strategy using High Density PWM Converter in Single Phase to Three Phase Drive System for WECS Application
}

\author{
Mrs. J. Steffy \\ Assistant Professor, Electrical and Electronics Engineering, Apollo Engineering College, Chennai
}

\begin{abstract}
The proposed system permits to reduce the rectifiers switching currents, the harmonics distortion at the input converter side, and improvements on the fault tolerance characteristics. Single phase to three phase drive system composed of High density PWM rectifier, a three phase inverter and PMSG. The feed-forward method can help the auxiliary active energy storage circuit working as a parallel active power filter for filtering out the low frequency ripple current from the H-bridge rectifier. The total energy loss of the proposed system may be lower than that of a conventional one. Suitable control strategy including the pulse width modulation technique is developed.
\end{abstract}

Index Terms: Ac-dc-ac power converter, drive system, parallel converter.

\section{INTRODUCTION}

High density PWM converter is used to improve the power capability, reliability and efficiency. This technique can be employed to improve the performance of active power filter, un interruptible power supplies, fault tolerance of induction motor and three phase drives. Usually the operation of converters in parallel requires a transformer for isolation. The weight, size, and cost associated with the transformer is high hence makes the system bulky. In this proposed parallel converters isolation transformers are not used so that this system is highly reliable.

Single phase to three phase drive system composed of single phase High Density rectifiers and a three phase inverter. This parallel converter topology permits to reduce the rectifier switch current, the total harmonic distortion (THD) of the grid current with same switching frequency with same THD of the grid current and to increase the fault tolerance characteristics. The control strategy employed for this single phase to three phase conversion is PID controller and harmonics can be reduced using PWM techniques. .

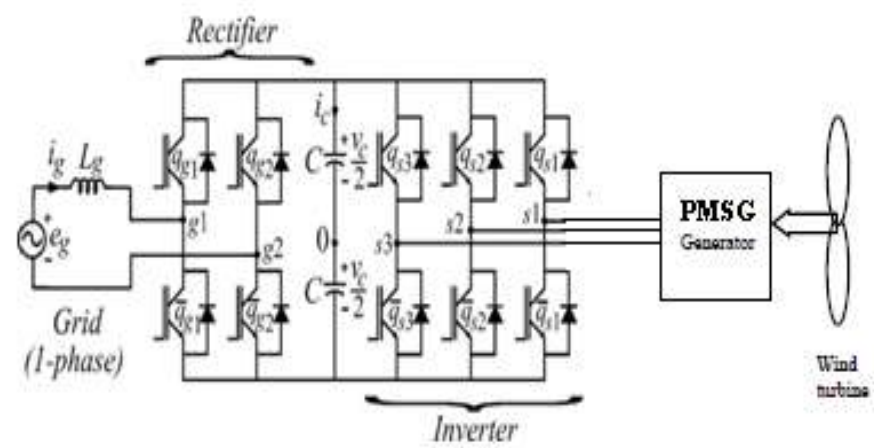

Fig. 1 conventional single phase to three phase drive system

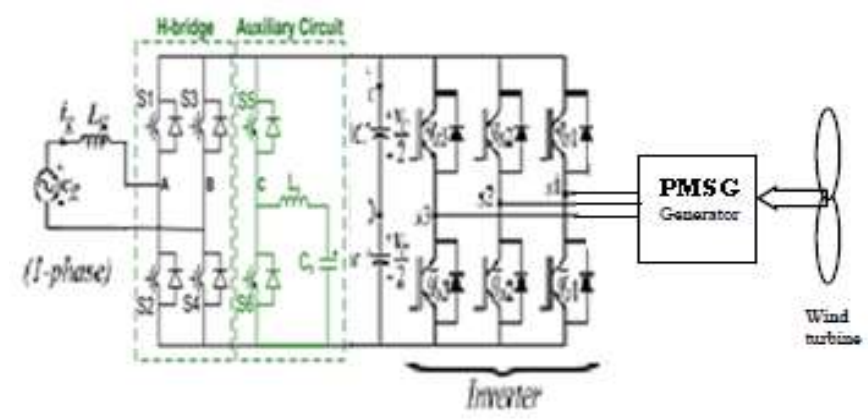

Fig.2 Proposed single phase to three phase drive system 


\section{II.AUXILLARY CIRCUIT}

For a practical implementation, it is not easy to determine the auxiliary capacitor current reference A more straightforward, but similar current filter method is used. The compensation current is used to regulate the low frequency ripple current. the triangular shaded area is the current waveform of the compensation current.

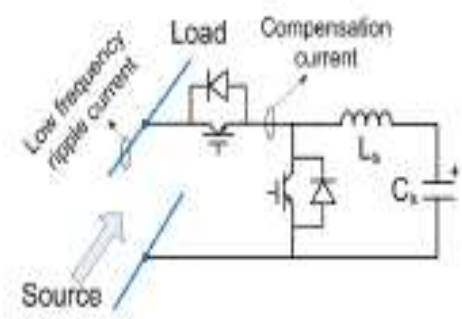

Figure 3.Auxillary circuit working as parallel active ripple current filter

Using the previous method, the average compensation current within one switching period should be equal to the low frequency ripple current.

\section{III.PWM STRATEGY}

The control of output voltage control involves the variation of dc input voltage; regulate the variation of inverters and to satisfy the constant volts and frequency control requirements. The most efficient method of controlling inverter output is pulse width modulation technique (PWM). The change of position of voltage pulse leads also to change in the distribution of the zero instantaneous voltage. The parameter ' $\mu$ ' influence the harmonic distortion of the voltages generated by the rectifiers. When $\mu=0$ or $\mu=1$ the zero voltages are placed at the beginning or at the end of the switching period. When $\mu=0.5$ they are distributed equally at the beginning and at the end of the half period. It is similar to distribution of the zero-voltage vector in three phase inverter.

\section{IV.CONTROL STRATEGY}

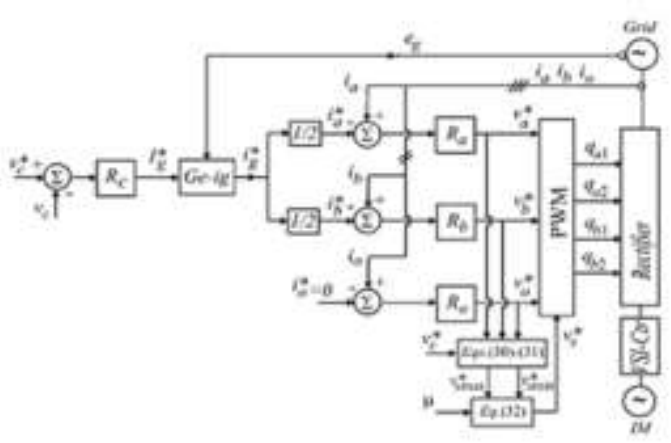

Fig 4.control block diagram

Control of rectifier has some objectives like to control the dc-link voltage and to make the power factor equals to one. The circulating current $\mathrm{i}_{0}$ in the rectifier needs to be controlled. The dc link voltage $\mathrm{v}_{\mathrm{c}}$ is adjusted to its reference value $\mathrm{v}_{\mathrm{c}}{ }^{*}$ using the PID controller $\mathrm{R}_{\mathrm{c}}$. To control power factor and harmonics in the grid side, the instantaneous reference current $\mathrm{i}_{\mathrm{g}} *$ must be synchronized with voltage $\mathrm{e}_{\mathrm{g}}$ for the voltage oriented control (VOC) for the three phase system. The control of rectifiers can be implemented by the controller $R_{a}$ and $R_{b}$. The control system is composed of PWM commanded and a torque/flux strategy.

\section{HARMONIC DISTORTION}

The harmonic distortion of the converter voltages has been evaluated by using the weighted THD (WTHD). WTHD can be calculated by using the fallowing formula,

WTHD $(\mathrm{p})=100 / \mathrm{a}_{1}$

Where

$$
\sqrt{\sum_{i=2}^{p}(a i / i) 2}
$$


$a_{1}$ is the amplitude of the fundamental voltage, $a_{i}$ is the amplitude of $i^{\text {th }}$ harmonic and $p$ is the number of harmonics taken into consideration.

The resultant voltage $\mathrm{v}_{\mathrm{ab}}$ is used to regulate the harmonic distortion of the utility grid. The WTHD of the proposed topology in double-carrier with $\mu=0$ or $\quad \mu=1$ is close to $63 \%$ of that conventional bridge rectifier with $\mu=0.5$ and the switching frequency can be reduced upto $60 \%$.

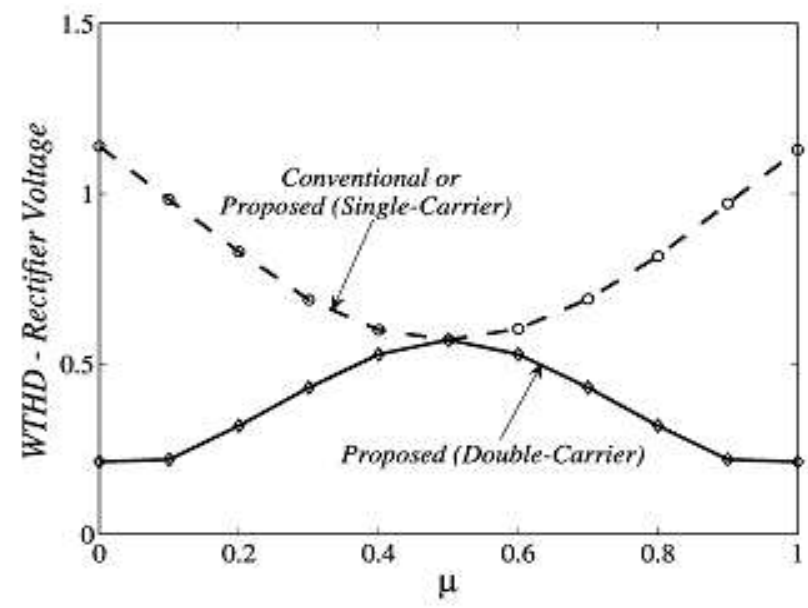

Figure 5. Harmonic distortion curve

For the double-carrier the voltage $\mathrm{v}_{\mathrm{ab}}$ has smaller amplitude and better distribution along the half switching period than that of single carrier. the optimal rectifier operation is obtained with double carrier making $\mu=0$ or $\mu=1$ with the reduced losses and increased efficiency

\section{VI.INPUT INDUCTORS}

The curve indicates total harmonic distortion for different values of $1_{\mathrm{n}}$. for $1_{\mathrm{n}}>0.4 \quad\left(\mathrm{l}_{\mathrm{g}}>0.4 \mathrm{l}_{\mathrm{g}}\right)$ the THD of the grid current of the proposed topology is smaller than that of the conventional topology. The harmonic distortion of the rectifier currents is higher than that of the grid current $i_{g}$. The adequate choice of the PWM strategy permits to operate with minimum harmonic distortion.

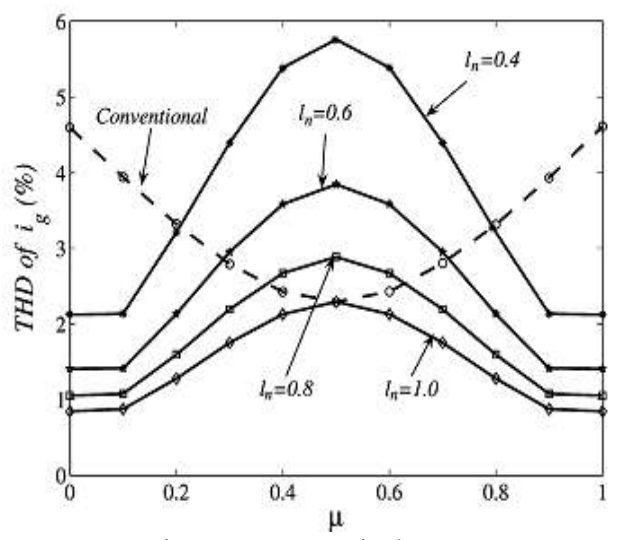

Figure 6. Input inductor

\section{VII.FAULT COMPENSATION}

The fault compensation is achieved by reconfiguring the power converter topology with help of isolating devices and connecting devices. Fault identification system (FIS) detects and locates the faulty switches, defining the leg to be isolated. If a fault in any switch of rectifier A has been detected by the control system, the whole rectifier needs to be isolated. This isolation procedure depends on the kind of fault detected. If an open-circuits failure is detected, the control system will open all switches of the rectifier A. on the other hand, if a short circuit is detected, the control system will turn on all switches related to rectifier A, and in this case, the fuses will open, and consequently, the rectifier will be isolated. 


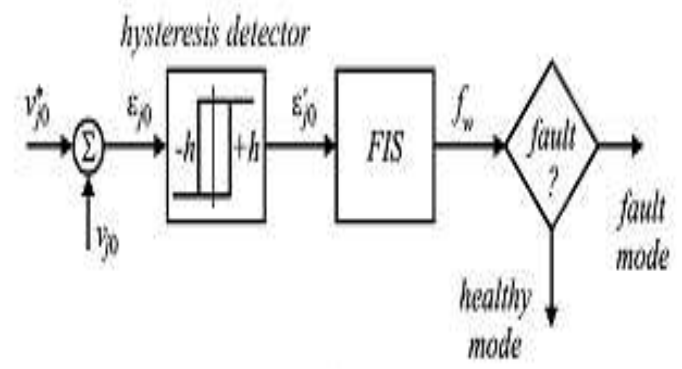

Figure 7.Fault compensation block

\section{VIII.SIMULATION RESULTS}

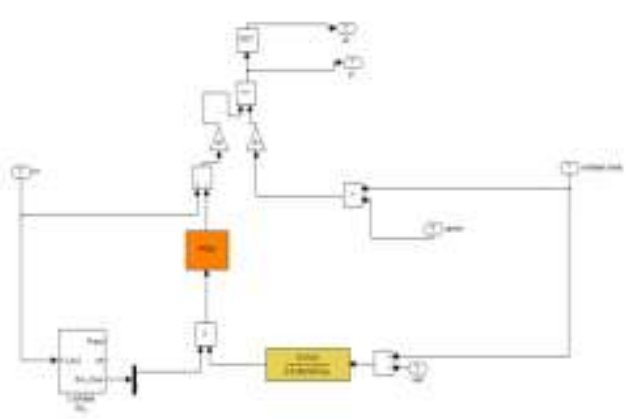

Fig 8.High density single phase rectifier controller block

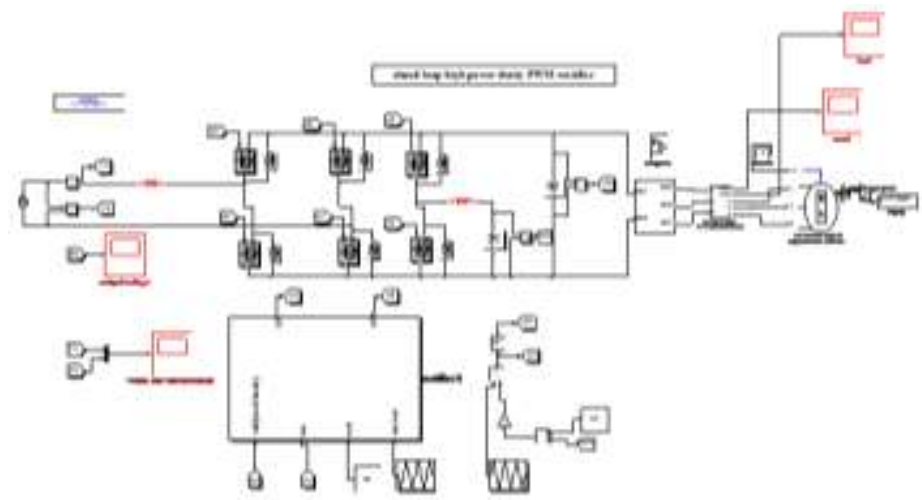

Fig 9. Proposed single phase to three phase drive system

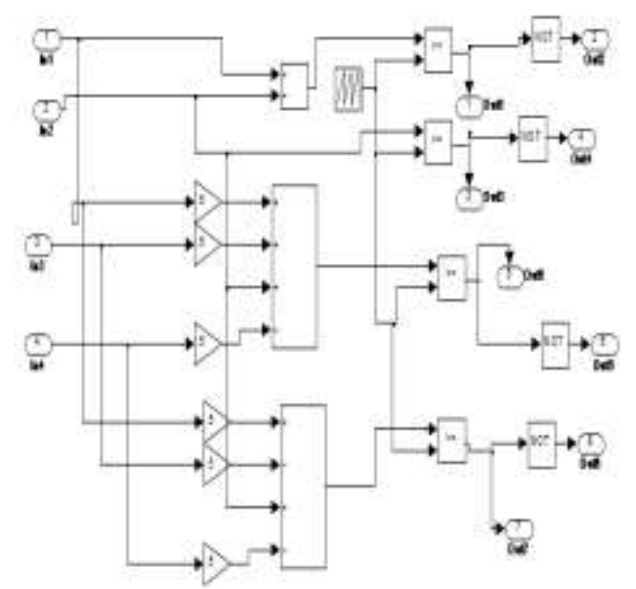

Fig 10.PWM generation block 
Vol. 6, Issue 4, April 2017

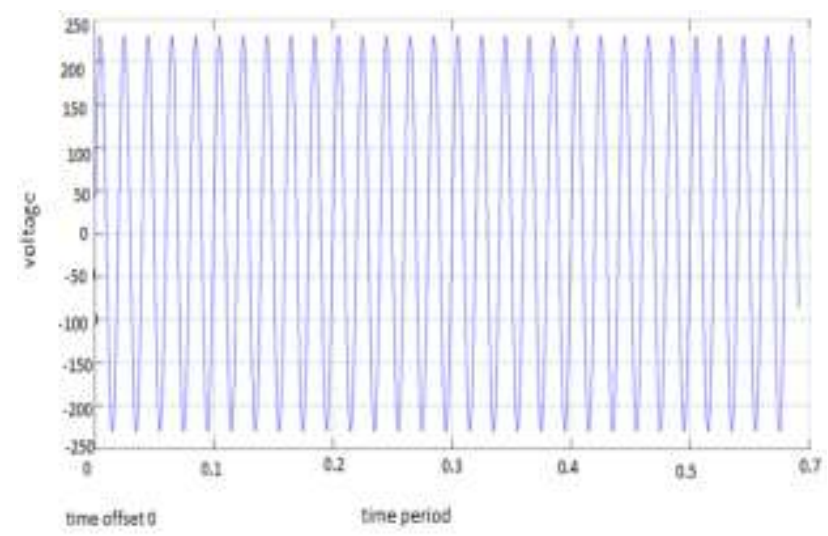

Fig 11.Input voltage (230v) curve

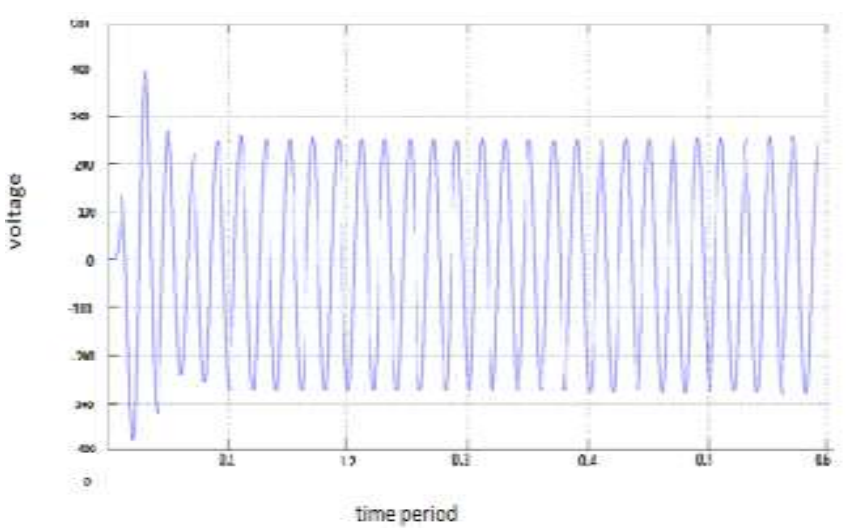

Fig 12. Output voltage (400v) curve

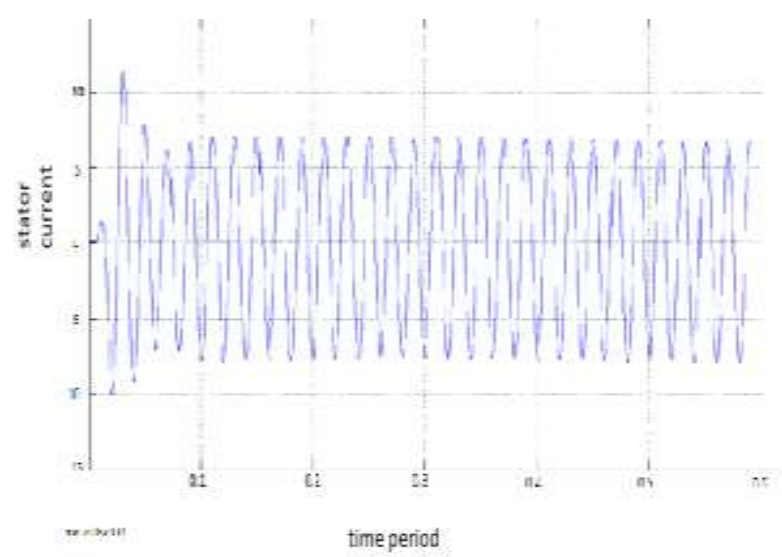

Fig 13.stator current curve

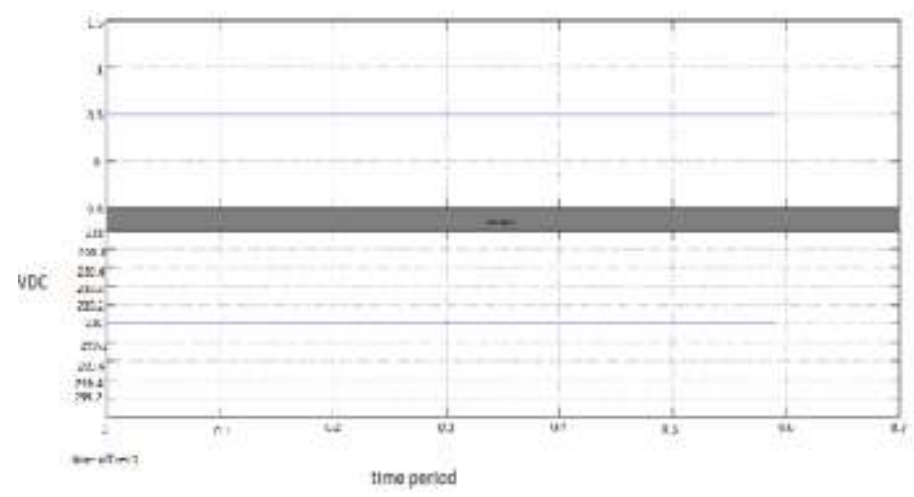

Fig 14. $\mu$ and de voltage curve 
TABLE I Normalized THD of the dc link current of the proposed converter

\begin{tabular}{|lc|c|}
\hline \multicolumn{2}{|c|}{ Topology $(\mathrm{PWM})$} & $\mathrm{THD}_{\mathrm{p}} / \mathrm{THD}_{\mathrm{c}}$ \\
\hline Proposed & $($ single $\mu=0.5)$ & 0.994 \\
\hline Proposed & $($ double $\mu=0.5)$ & 1.002 \\
\hline Proposed & double $\mu=0)$ & 0.717 \\
\hline
\end{tabular}

TABLE II Efficiency of the proposed system

\begin{tabular}{|l|l|l|l|}
\hline (np/nc-1) \\
\hline Frequency/inductor & S-Ca $\boldsymbol{\mu}=\mathbf{0 . 5}$ & D-Ca $\boldsymbol{\mu}=\mathbf{0 . 5}$ & D-Ca $\boldsymbol{\mu}=\mathbf{0}$ \\
\hline $10 \mathrm{KHZ} /\left(\mathrm{Lg}^{\prime}=\mathrm{Lg}\right)$ & $-1.60 \%$ & $-1.47 \%$ & $-0.41 \%$ \\
\hline $10 \mathrm{KHZ} /\left(\mathrm{Lg}^{\prime}=\mathrm{Lg} / 2\right)$ & $3.12 \%$ & $3.25 \%$ & $4.36 \%$ \\
\hline $5 \mathrm{KHZ} /\left(\mathrm{Lg}^{\prime}=\mathrm{Lg}\right)$ & $-0.74 \%$ & $-0.27 \%$ & $1.72 \%$ \\
\hline
\end{tabular}

\section{IX.LOSSES AND EFFICIENCY}

When the rectifier operates with a switching frequency equal to $5 \mathrm{KHZ}$, the conduction and switching losses of proposed topology were $70 \%$ and $105 \%$, respectively, of the corresponding losses of the conventional topology. The efficiency of the topologies operating with a switching frequency equal to $10 \mathrm{KHZ}$ and $5 \mathrm{KHZ}$ was evaluated experimentally. In the other cases, the proposed configuration with double-carrier and $\mu=0$ presents higher efficiency than the conventional one.

\section{X.COSTS AND APPLICATIONS OF CONFIGURATION}

The initial investment of the proposed system is higher than that of the standard one, since the number of switches and devices such as fuses and switches is highest. The cost of this schedule can be high and this justifies the high initial investment inherent of fault-tolerant motor drive systems. The initial investment can be justified if the THD or losses of the conventional system is a critical factor. Parallel converter system permits to employ extra switches without increasing the final price of converter. In Brazil, it is quite common to have a single-phase distribution system and a demand to supply a three-phase motor in electric generating power station (WECS).

\section{REFERENCES}

[1] "A New Single-phase to Three-phase Converter with Active Input Current Shaping for Low Cost ac Motor Drives", IEEE TRANSACTIONS ON INDUSTRY APPLICATIONS, VOL. 29, NO. 4, JULY/AUGUST 1993.

[2] "Induction Motor Drive System for Low-Power Applications", IEEE TRANSACTIONS ON INDUSTRY APPLICATIONS, VOL. 35, NO. 1, JANUARY/FEBRUARY 1999.

[3] "Control of the Single-Phase Three-Leg AC/AC Converter", IEEE TRANSACTIONS ON INDUSTRIAL ELECTRONICS, VOL. 53, NO. 2, APRIL 2006.

[4] "Modulation Techniques for a Low-Cost Single-Phase to Three Phase Converter", IEEE TRANSACTION ON INDUSTRY APPLICATION 2004

[5] "A Simple Sensorless Method for Sinusoidal PWM Converters", IEEE TRANSACTION ON POWER ELECTRONICS 1997.

[6] "Direct Power Control of PWM Converter without Power-Source Voltage Sensors", IEEE TRANSACTIONSON INDUSTRY APPLICATIONS, VOL. 34, NO. 3, MAY/JUNE 1998.

[7] “A Maximum Torque Control with a Controlled Capacitor for a Single-phase Induction Motor", IEEE TRANSACTIONS ON INDUSTRIAL ELECTRONICS, VOL. 42, NO. I, FEBRUARY 1995.

[8] "Control of Circulating Current in Two Parallel Three-Phase Boost Rectifiers", IEEE TRANSACTIONS ON POWER ELECTRONICS, VOL. 17, NO. 5, SEPTEMBER 2002

[9] "Circulating Current Minimization in High-Frequency AC Power Distribution Architecture with Multiple Inverter Modules Operated in Parallel”, IEEE TRANSACTIONS ON INDUSTRIAL ELECTRONICS, VOL. 54, NO. 5, OCTOBER 2007. 